Da Silva Borba, Alexandra. Análise sobre a hidroeléctrica barra grande a partir do conceito de espaço de Milton Santos. GeoGraphos. [En línea]. Alicante: Grupo Interdisciplinario de Estudios Críticos y de América Latina (GIECRYAL) de la Universidad de Alicante, 18 de mayo de 2013, vol. 4, no 52, p. 484-498. [ISSN: 2173-1276].

\title{
ANÁLISE SOBRE A HIDROELÉTRICA BARRA GRANDE A PARTIR DO CONCEITO DE ESPAÇO DE MILTON SANTOS
}

\author{
Alexandra Borba da Silva \\ Estudante de Mestrado em Geografia \\ Universidade Estadual Paulista (UNESP) - Campus Presidente Prudente \\ (Campos Novos, Santa Catarina, Brasil) \\ Correio eletrônico: alecamponesa@gmail.com
}

Recibido: 2 de febrero de 2013. Devuelto para revisión: 12 de marzo de 2013. Aceptado: 20 de mayo de 2013

\section{RESUMO}

O artigo reflete a produção do espaço a partir da construção da Usina Hidroelétrica Barra Grande, no sul do Brasil. A referida usina trouxe antes mesmo de sua construção diversos simbolismos capazes de legitimar a sua necessidade para a região que seria instalada. A hidrelétrica, objeto técnico criado dentro de um sistema de objetos da racionalidade capitalista pensado a nível global foi introduzida num espaço transformando-o radicalmente. A partir da contribuição de Milton Santos é traçada uma reflexão no sentido de perceber o objetivo da instalação da hidrelétrica: o acumulo da maior mais-valia. Ao mesmo tempo se construíram a reação e a força do lugar, capazes de desencadear um processo de valorização do lugar, conflitar com a racionalidade capitalista e propor alternativas de produção do espaço.

Palavras-chave: Hidroelétrica Barra Grande, produção do espaço, técnicas. 


\title{
ANÁLISIS SOBRE LA HIDROELÉCTRICA BARRA GRANDE A PARTIR DEL CONCEPTO DE ESPACIO DE MILTON SANTOS
}

\section{RESUMEN}

El artículo refleja la producción del espacio a través de la construcción de la Central Hidroeléctrica Barra Grande, en el sur de Brasil. La referida planta trajo, incluso antes de su construcción diversos simbolismos capaces de legitimar su necesidad para la región en la que seria instalada. La hidroeléctrica, objeto técnico creado dentro de un sistema de objetos de la racionalidad capitalista a nivel global, fue introducida en un espacio transformándolo radicalmente. A partir de la contribución de Milton Santos es trazada una reflexión en el sentido de percibir el objetivo de la instalacion de la hidroeléctrica: la acumulación de mayor plusvalía. Al mismo tiempo se construye la reacción y la fuerza del lugar, capaces de desencadenar un proceso de valorización del mismo, confrontar con la racionalidad capitalista y proponer alternativas de produción de espacio.

Palabras clave: Hidroeléctrica Barra Grande, producción de espacio, técnicas.

\section{BARRA GRANDE HYDROELECTRIC POWER STATION ANALYSIS GIVEN MILTON SANTOS CONCEPT OF TERRITORIAL PRODUCTION}

\begin{abstract}
This article reflects the territorial production from the building of the Barra Grande Hydroelectric Power Station, in Southern Brazil. This Hydropower Station brought even before its construction different symbolisms able to legitimate its need for the region in which it would be installed. The Hydropower Station, a technical object created inside an object system from a capitalism rationalism thought in a global level was introduced inside a territory transforming it radically. A reflection is made given Milton Santos contribution in order to perceive the goal of the Hydroelectric Power Station installation: the accumulation of capital gains. At the same time the strength and reaction of the place were built, able to unleash a process of valuation of the place, confronting capitalism rationality and proposing territorial production alternatives.
\end{abstract}

Key words: Barra Grande Hydroelectric Power Station, Territorial Production, Technics.

\section{INTRODUÇÃO}

O artigo a seguir é um esforço de entrelaçar a análise sobre as hidrelétricas, em especial Barra Grande, com o conceito de espaço do geógrafo Milton Santos na sua riquíssima reflexão e teorização no livro A natureza do espaço (1996). O livro, produzido em sua fase amadurecida intelectualmente traz uma vasta revisão bibliográfica da geografia em especial, bem como da sociologia, contribuindo com inúmeras criticas e avaliações acerca dos conceitos e noções produzidas por geógrafos das mais variadas correntes teóricas. 
Tentaremos utilizar dos conceitos e análises do autor para compor uma reflexão sobre o setor elétrico, especificamente o caso da UHE Barra Grande. A referida hidrelétrica foi e continua sendo determinante na produção do espaço na sua região de abrangência, e porque não dizer, a nível nacional e internacional. A própria produção da energia elétrica, a transformação no espaço e na paisagem, a transformação na configuração espacial tanto do ponto de vista da natureza, da economia, da cultura e das mudanças sociais.

\section{CONCEITOS DA GEOGRAFIA PARA A ANÁLISE DO SETOR ELÉTRICO}

M. Santos inicia o livro se perguntando: o que é a geografia e qual seu objeto. Segundo o autor a geografia clássica ocupou-se por demasiado em descrever o objeto, mas a tarefa deve ir mais além. Fazer análise, compreender e refletir sobre o mesmo. Para ele, o objeto central da geografia é a produção do espaço geográfico.

A produção do espaço, objeto central da geografia, abrange inúmeras formas de relação da sociedade com a natureza. Para o autor, objeto e método são indissociáveis para a análise. É necessário ter um conjunto de conceitos que deem conta de compreender o mais profundamente possível o objeto, mantendo coerência intelectual.

Mas o que seria o espaço? Para M. Santos (1996, p. 51), "é um conjunto indissociável, solidário e também contraditório, de sistema de objetos e sistema de ações". Indissociável porque os objetos não existem em si mesmos, pressupõe ação, são produto das ações; enquanto que as ações só são concretizadas nos objetos e produzem novos objetos. O autor acrescenta que os conceitos de relações de produção e forças produtivas utilizados na análise marxista seriam respectivamente semelhantes aos conceitos de sistemas de ações e sistemas de objetos. Porém, que na realidade atual os conceitos anteriores não dão conta de explicar a complexidade, tornando necessários paradigmas mais específicos que deem conta de explicar o espaço tempo.

O autor também traz presente um elemento importante do método materialista histórico dialético, que é a totalidade. Segundo ele, apesar da geografia analisar uma parte da realidade, deve estar sempre "preocupada" em estabelecer relação com o todo da sociedade, com as questões globais. No caso especifico da análise sobre a UHE Barra Grande precisaremos ter presente a sua relação dentro do setor elétrico brasileiro como um sistema de objetos e de ações, interconectados e produto de um determinado modo de produção, com avanço das técnicas e que exige um padrão na geração de energia.

Outro conceito importante do autor que nos interessa nesta reflexão é técnica e objeto técnico. A técnica é a principal forma de relação do ser humano com a natureza, na produção do espaço. As técnicas são fundamentais na compreensão do espaço tempo. Porém, para o autor, as técnicas são produzidas de acordo com interesses do sistema, e o motor principal é o acúmulo da maior mais-valia.

Os objetos técnicos são os objetos construídos a partir da ação humana e o espaço passa a ser marcado por esses objetos que lhe dão um conteúdo técnico. As hidrelétricas ${ }^{1}$ são um conjunto de técnicas que combinadas compõe um amplo sistema de geração de eletricidade,

\footnotetext{
${ }^{1}$ Neste artigo se utilizará os termos "hidrelétrica/s" e "barragem/ns" como sinônimos.
} 
as quais abastecem grande parte da demanda brasileira de energia. A hidrelétrica Barra Grande, construída no Rio Pelotas na divisa dos estados do Rio Grande do Sul e Santa Catarina, faz parte desse conjunto de técnicas do setor elétrico.

"Toda criação de objetos responde a condições sociais e técnicas presentes num dado momento histórico" (Santos, 1996, p. 56). Esse objeto técnico, hidrelétrica, reflete um determinado espaço tempo. Não é própria de um momento em que ainda a humanidade não havia criado a eletricidade e se usavam outras fontes, especialmente a lenha para combustão. Também não é própria de lugares que não tenham rios com água abundante. As hidrelétricas ajudam a compreender um espaço tempo que necessita de energia elétrica para movimentar indústrias, transporte, comunicações, residências, e que provém de um conjunto de técnicas capaz de produzir e transportar a energia.

Santos coloca a seguinte questão: em que medida a noção de espaço pode contribuir à interpretação do fenômeno técnico e qual o papel do fenômeno técnico na produção e transformação do espaço geográfico. Para o autor, o fenômeno técnico pode ser uma metadisciplina da geografia. Para o objeto em questão, a hidrelétrica, pode ser considerada um fenômeno técnico que produz e transforma o espaço geográfico. Ao mesmo tempo o espaço geográfico influencia na construção do fenômeno técnico, a hidrelétrica. Essa análise será feita ao longo do artigo.

\section{A PRODUÇÃO DO ESPAÇO A PARTIR DA UHE BARRA GRANDE}

A Usina Hidrelétrica Barra Grande é uma das sete grandes barragens construídas e que estão em operação na Bacia do Rio Uruguai ${ }^{2}$. Está localizada no rio Pelotas, entre os municípios de Anita Garibaldi/SC e Pinhal da Serra/RS. O projeto previsto na década de 60 por estudos do inventário hidrelétrico brasileiro encomendado pela Eletrobrás ${ }^{3}$ previa a construção de 25 grandes barragens ao longo da Bacia. Barra Grande foi construída entre 2001 e 2005, iniciando a gerar energia em novembro do último ano.

O setor elétrico brasileiro, construído a partir de uma infinidade de avanços técnicos permite um sem numero de outros avanços e construção de outros objetos técnicos. Parafraseando Santos, aumentam a autonomia relativa da humanidade em relação à natureza. A energia elétrica é utilizada como bem de consumo pelas residências, transporte, mas também como um bem de produção ao ser utilizada na indústria, agricultura, etc. Não podemos imaginar uma casa hoje sem geladeira, chuveiro, televisão, ferro de passar roupas, etc. Também não conseguimos imaginar construir um amplo sistema industrial movido somente com energia

\footnotetext{
${ }^{2} \mathrm{Na}$ Bacia do Rio Uruguai foram construídas sete grandes hidrelétricas que estão gerando energia: UHE Passo Fundo, UHE Ita, UHE Machadinho, UHE Barra Grande, UHE Campos Novos, UHE Monjolinho, UHE Foz do Chapecó. Além dessas, a UHE Garibaldi no Rio Canoas, afluente do Rio Uruguai está em fase final de construção com previsão de gerar energia ainda em 2013.

3 “A Eletrobras é uma empresa de capital aberto, controlada pelo governo brasileiro, que atua nas áreas de geração, transmissão e distribuição de energia elétrica". Foi criada em 1962 para ser responsável pela festão do setor elétrico brasileiro. Fonte: Eletrobras.
} 
térmica ou nuclear. Ou seja, a hidrelétrica está conectada com uma infinidade de outras técnicas, e, portanto, gera varias outras indústrias que produzem inúmeras mercadorias.

As hidrelétricas são também um exemplo claro do que o autor chama de divisão internacional do trabalho e divisão territorial do trabalho. Grande parte da energia provinda das hidrelétricas no Brasil (25\%) é consumida por empresas eletrointensivas, também chamados de consumidores livres. Por consumirem uma grande quantidade de energia podem comprar livremente direto das empresas produtoras. Essa energia é empregada na produção de produtos como ferro-liga, alumínio, celulose que por sua vez são exportados. Ou seja, faz parte de uma cadeia produtiva onde o Brasil, bem como América Latina, é exportador de matéria-prima e que para essa produção necessita grande quantidade de energia elétrica. É a divisão internacional do trabalho determinada também pela divisão na produção das riquezas a nível mundial e do papel exercido nos países dentro do sistema econômico mundial.

No caso das hidrelétricas a divisão territorial do trabalho para sua construção é visível, bem como os conflitos surgidos. Podemos citar no caso de Barra Grande, onde em média estiveram trabalhando cinco mil trabalhadores por mês, sendo grande parte oriundos de outras regiões do Brasil, especialmente do Nordeste. Ainda no caso da UHE Foz do Chapecó, construída no Rio Uruguai, podemos visualizar algumas informações de como eram organizados os trabalhadores e os conflitos surgidos a partir desse processo. Silva em estudo de caso sobre a Hidrelétrica relata que:

Neste sentido o espaço do canteiro de obras acabava por ser o mundo dos trabalhadores, pois eles trabalhavam, dormiam, se alimentavam, se divertiam, tudo no mesmo espaço praticamente fechados e convivendo com as mesmas pessoas.

Com isso a empresa conseguia um melhor aproveitamento do trabalho dos trabalhadores, pois os mesmos estavam próximos ao local de trabalho. Ao mesmo tempo era um espaço gerador de conflitos por estarem num grande número de pessoas, praticamente confinadas e a maioria delas eram homens. (Silva, 2011, p. 30).

Essa forma de organização do trabalho na construção das hidrelétricas possibilita enormes conflitos, pois além da situação social, no caso, confinamento, ainda existem problemas de distancia por estarem em regiões longínquas de suas famílias e com baixos salários.

Milton Santos relata que o sistema capitalista atinge a todos, porém de forma distinta dependendo do tempo e do espaço. Podemos a partir de essa afirmação apontar elementos sobre as formas que a UHE Barra Grande atingiu e/ou atinge diferentes pessoas: os trabalhadores/as na construção da obra migraram especialmente do Nordeste para realizar esse trabalho, enfrentando dificuldades, baixos salários, distancia das famílias; as famílias que tiveram suas terras alagadas precisaram lutar contra a empresa construtora para que recebessem indenização ou reassentamentos para construírem uma nova moradia; pessoas que dependiam do local atingido para sobreviver, tais como motorista de ônibus escolar, motorista 
de caminhão de leite, professores/as das escolas em áreas atingidas, comerciantes das cidades atingidas viram diminuída a intensidade do seu trabalho e retorno econômico, ou até mesmo perderam seu trabalho e tiveram que procurar emprego em outros locais.

A hidrelétrica é uma técnica globalizada, uma forma de gerar energia conhecida no mundo todo e utilizada em diversos locais. Segundo Santos, esse caráter sistêmico das técnicas é que permite a existência das empresas multinacionais, que atuam em diversos países e em ramos diferentes da economia. Em Barra Grande, a principal acionista, ALCOA S.A ${ }^{4}$, multinacional estadunidense tem inúmeras empresas da qual tem ações no Brasil, principalmente na área de produção de alumínio e, por conseguinte na produção de energia elétrica. $\mathrm{O}$ alumínio tem como uma de suas características a necessidade de grande quantidade de energia no seu processo produtivo, por isso o investimento feito pela empresa nas hidrelétricas. Isso quer dizer que o interesse principal não está em gerar energia para a maioria da população, mas sim para garantir que haja energia suficiente para o seu consumo próprio.

Barra Grande tem garantia física de 380,6 MWH médios e potência máxima instalada de 698 $\mathrm{MWh}^{5}$. Essa energia é vendida para empresas de distribuição ou para consumidores livres. A energia que é vendida às distribuidoras é consequentemente vendida aos consumidores cativos, ou seja, a população de forma geral. Esses consumidores são na maioria residências, comércio, serviços públicos; enquanto que a energia vendida a consumidores livres é consumida nas grandes indústrias eletrointensivas.

A energia provinda da hidroeletricidade é mais barata e eficiente que outras fontes convencionais, por isso é a mais utilizada no Brasil sendo responsável por $68,89 \%$ da energia utilizada $^{6}$. É a forma de gerar energia que produz maior mais-valia. Como afirma Santos (1996) a maior mais-valia busca constantemente ultrapassar a si mesma, e é ela que controla o avanço das técnicas e das tecnologias. Isso faz com que empresas eletrointensivas, que necessitam de muita energia para seu processo produtivo instalem-se em países com capacidade de geração hidrelétrica. $\mathrm{O}$ custo para produzir a mesma quantidade de ferro-liga num país que queime petróleo para gerar energia seria mais alto e consequentemente a maisvalia extraída seria menor.

O fato da hidrelétrica permitir a atuação das multinacionais por serem técnicas globalizadas também permite que as empresas comandem a produção de distintos locais do mundo, no caso a ALCOA desde os Estados Unidos. Isso tanto no negócio hidrelétrico, como no negócio produção de alumínio. Na Bacia do Rio Uruguai grande parte das empresas donas das usinas são privadas, a grande maioria multinacionais estrangeiras, e algumas multinacionais brasileiras, como podemos ver na figura 1.

\footnotetext{
${ }^{4}$ A UHE Barra Grande é de propriedade da BAESA (Barra Grande Energética S.A.). A BAESA é um Consórcio formado pelas empresas Alcoa Alumínio S.A. (42.18\%), CPFL - Geração de Energia S.A. (25\%), CBA Companhia Brasileira de Alumínio (15\%), Camargo Correa Cimentos S.A. (9\%) e DME Energética Ltda. $(8,82 \%)$. ${ }^{5}$ Fonte: (ANEEL - BIG - Banco de Informações de Geração - Capacidade de Geração do estado de SANTA
CATARINA).

${ }^{6}$ Fonte: (BIG - Banco de Informações de Geração - ANEEL).
} 
Figura 1. Proporção de participação das empresas estatais e privadas nas sete hidrelétricas que estão gerando energia, construídas na Bacia do Rio Uruguai

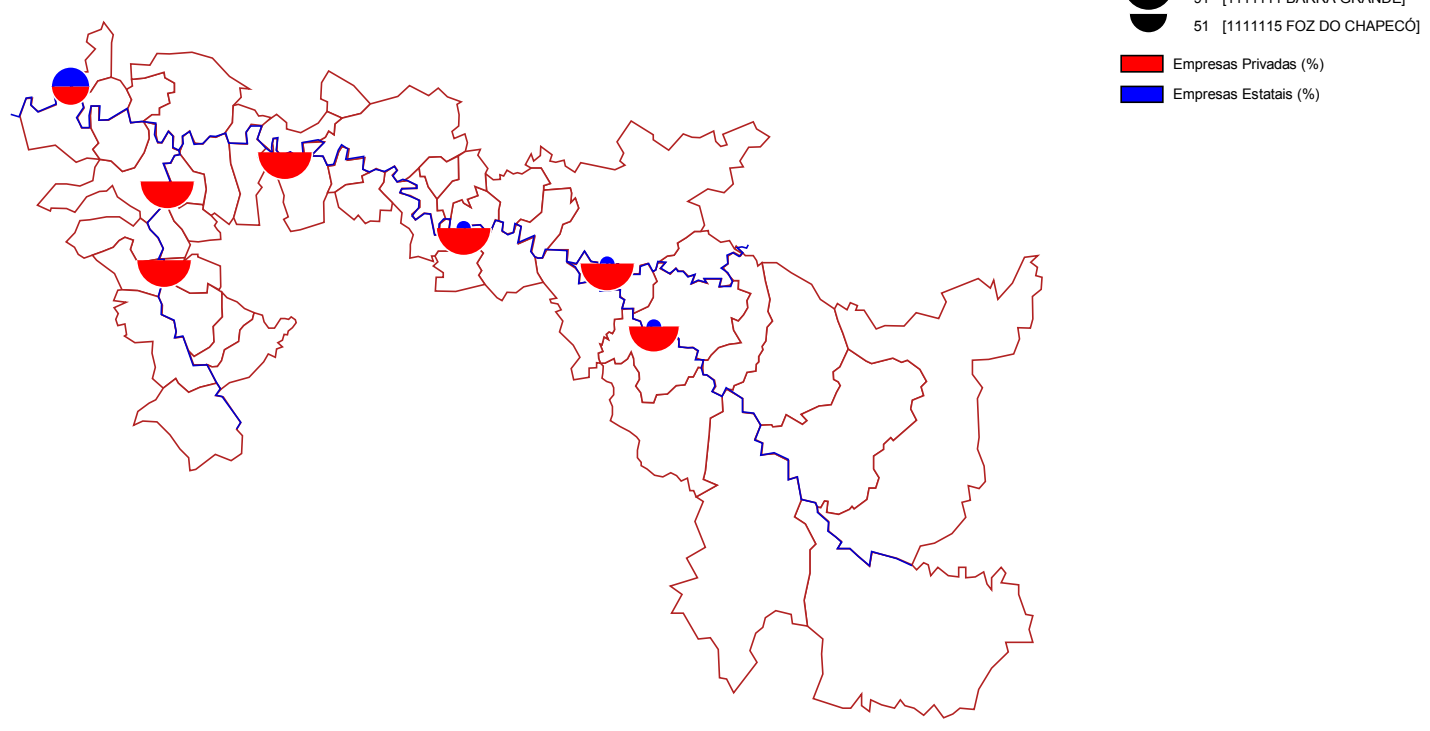

Elaborado com Philcarto * 19/2/2013 10:03:13 * http://philcarto.free.fr

Fonte: ANEEL. Elaboração própria.

Neste mapa com os municípios atingidos pelas sete hidrelétricas vemos que a grande parte das ações em cada UHE é privada. Empresas estrangeiras dos Estados Unidos (Alcoa), França (GDF), Bélgica (Suez) controlam desde seus países atividades econômicas no sul do Brasil. A produção do espaço é influenciada diretamente do global para o local. São interesses globais agindo no local.

A mercadoria produzida, ou como conceitua Santos, o objeto técnico criado tem uma função mercantil e também simbólico:

"quando nos dizem que as hidrelétricas vêm trazer, para um país ou para uma região, a esperança de salvação da economia, da integração no mundo, a segurança do progresso, tudo isso são símbolos que nos permitem aceitar a racionalidade do objeto que, na realidade, ao contrário, pode exatamente vir destroçar a nossa relação com a natureza e impor relações desiguais" (p. 173). 
Nesse sentido o exemplo de Barra Grande é oportuno. Desde o inicio da instalação na região das empresas responsáveis pelo estudo, e posteriormente pela construção da obra tiveram uma preocupação com as ideias e o simbolismo que poderia representar o empreendimento. $\mathrm{O}$ investimento desde as escolas, Clubes de mães, e até mesmo o patrocínio em festas comunitárias foi decisivo para influenciar no senso comum a ideia de que a hidrelétrica seria construída para gerar desenvolvimento regional.

Barra Grande alagou uma área de 99,99 quilômetros quadrados, o que equivale a 9.999 hectares de terra ${ }^{7}$. Por serem terras próximas ao rio, com grande área verde eram muito férteis para a agricultura, e habitada por famílias camponesas que sobreviviam com poucos hectares de terra, produzindo alimentos para subsistência. Segundo dados da BAESA, foram indenizadas de alguma forma 1.520 famílias, sendo 959 indenizações em dinheiro, 249 na modalidade cartas de crédito, 193 na modalidade Reassentamento, 5 Remanescentes e 114 de outras formas $^{8}$. O remanejamento, no entanto, não se deu de forma pacifica e as famílias realizaram durante vários anos um processo de organização que forçou a empresa ressarcir de forma melhor adequada os prejuízos causados.

A barragem de Barra Grande foi uma das mais polêmicas na Bacia do Rio Uruguai, no que diz respeito à questão ambiental. A empresa ENGEVIX, tradicional em obras no setor elétrico, na elaboração de Estudos de Impacto Ambiental (EIA-RIMA) omitiu dados em relação à área que seria inundada pela usina. No estudo (1997) havia a descrição da existência de capoeirões, pequenas culturas, capoeiras ciliares baixas e campos com arvoredos esparsos. Somente em 2003, com a obra construída, momento em que a BAESA encaminhou o pedido de supressão da floresta ao IBAMA é que o mesmo foi realizar vistoria a campo, houve pressões de várias entidades, e então se constatou a existência da mata nativa. No entanto, a Licença de Operação foi emitida, justificada em base no investimento econômico realizado até aquele momento. $\mathrm{O}$ que prevaleceu na decisão foi a racionalidade econômica.

"Esses objetos modernos - ou pós-modernos - vão do infinitamente
pequeno, como os microssistemas, ao extremamente grande, como,
por exemplo, as grandes hidrelétricas e as grandes cidades, dois
objetos enormes cuja presença tem um papel de aceleração das
relações predatórias entre o homem e o meio, impondo mudanças
radicais à natureza. Tanto as grandes hidrelétricas, quanto as grandes
cidades, surgem como elementos centrais na produção do que se

${ }^{7}$ Fonte: (ANEEL - Compensação Financeira Pela Utilização de Recursos Hídricos - Relação de Municípios Diretamente Atingidos).

${ }^{8}$ Foram três principais modalidades de indenização: a) Indenização em dinheiro: a empresa pagava para a família apenas as terras, casas, plantações que fossem alagadas, com valor estabelecido pela empresa. b) Carta de crédito: a família recebia um valor de 70 mil reais com o qual deveria comprar uma propriedade com terra, casa, lugar para sobreviver; e a empresa se tornava proprietária da antiga terra da família, tanto a parte alagada, bem como, com o que ficasse fora do alagamento, se fosse o caso. c). Os Reassentamentos são uma forma diferente de organizar, onde a empresa devia comprar grandes áreas de terra, repassar recurso em dinheiro para as famílias construírem benfeitorias (casas, galpões, estruturas comunitárias). Os lotes eram divididos conforme o tamanho das famílias. d) Modalidade remanescente: a empresa cedia uma terra que comprou de algum agricultor, próxima ao lago para outra família como forma de indenização. 
convencionou chamar de crise ecológica, cuja interpretação não pode ser feita sem levar em conta, mais uma vez, a tipologia dos objetos técnicos e as motivações de seu uso no presente período histórico". (Santos, 1997, p. 201).

O autor contribui com nossa reflexão na perspectiva de compreender a intencionalidade com que as técnicas são construídas em determinados locais. Apesar de impactarem o meio ambiente e aprofundarem, como no caso das barragens, a crise ecológica, tem um rosto sustentável, isso também é simbólico, criado na sociedade essa imagem das hidrelétricas. Barra Grande trouxe um enorme impacto à natureza ao alagar 2.077 hectares de cobertura florestal primária, 2.158 hectares de floresta em estagio avançado de regeneração, 2415 hectares de floresta em estagio médio e inicial de regeneração, além de mais de mil hectares de campos naturais. Grande parte da floresta era araucária, típica do Bioma Mata Atlântica, do qual faz parte esta região.

O modelo de geração de energia elétrica está totalmente a serviço das empresas multinacionais que têm grande demanda de energia no seu processo produtivo. Portanto, ao aproveitar a energia elétrica provinda das barragens, que são mais baratas e eficientes se comparadas com outras fontes, consegue-se uma eficiência produtiva maior, e consequentemente o aumento do valor a mais produzida, o aumento da exploração dos bens naturais e da força de trabalho.

O fato de alagar quase dez mil hectares de terra, também contribuiu significativamente para a transformação do espaço, que passou a cumprir um novo papel econômico, social e cultural. $\mathrm{O}$ que antes era terra que produzia alimentos e abrigava camponeses, pescadores, balseiros, passou a ser um lago com objetivo de comportar água que ao passar por uma grande queda e posteriormente por turbinas, gera eletricidade. Isso modificou o sistema de objetos do lugar, bem como o sistema de ações em relação a esses objetos. Tanto na relação com a terra e seu aproveitamento, o rio/lago, etc. No novo lago os camponeses não tem acesso à pesca, por exemplo.

Essa área passou a ser controlada pelas empresas que detêm a concessão da usina e deixou de ser de posse dos camponeses que ali moravam, ocorrendo, portanto, um processo de desterritorialização dos camponeses e territorialização das empresas. Porém, a produção do espaço desde o ponto de vista das empresas causando danos ambientais, sociais, culturais e econômicos também gerou conflitos. É possível perceber a reação dos camponeses atingidos, o que refletiremos a seguir.

\section{A Força do Lugar. Organização dos atingidos por barragens}

No Brasil, não existe legislação especifica que conceitue quem são os atingidos por barragens, nem como devem ser indenizados. Para tanto em cada obra construída as empresas determinam as formas e valores de indenização, e obviamente muitos conflitos acontecem, pois o interesse dos consórcios é diminuir os gastos. 
A historia dos atingidos por barragens na Bacia do Rio Uruguai está marcada por organização, lutas e enfrentamento às empresas construtoras de hidrelétricas, e conquistas de direitos. Desde a construção da UHE Itaipu Binacional, surgiram pequenos focos de luta, e posteriormente nas UHE Itá e Machadinho houveram significativos avanços em relação à garantia dos direitos das famílias que eram atingidas pelas barragens.

Nas UHE Itá e Machadinho, construídas na década de 90 e início de 2000, houveram grandes mobilizações dos atingidos para que as empresas reconhecessem seus direitos e pudessem ser indenizados. Segundo as empresas construtoras, somente eram atingidos quem era proprietário de terras alagadas. No entanto, os próprios atingidos entendem que todos/as aqueles/as que sofrem algum tipo de prejuízo frente à construção da hidrelétrica devem ser considerados atingidos e ser de alguma forma, indenizados (arrendatários, posseiros, meeiros, pescadores, professores, comerciantes). Como resultado das lutas, os atingidos conquistaram em 1987 a assinatura de um acordo que previa reassentamentos às famílias 9 . Até então a forma tradicional utilizada era pagamento em dinheiro. Com isso muitas famílias não conseguiam comprar terras e acabam por migrar para a periferia das cidades vizinhas.

Nessas duas primeiras hidrelétricas construídas (Itá e Machadinho) o inicio se deu sob coordenação da Eletrosul Centrais Elétricas S.A., subsidiária da Eletrobras, empresa estatal responsável pelo setor elétrico brasileiro. Porém, no período neoliberal na década de $90 \mathrm{com}$ a instituição do PND (Plano Nacional de Desestatização) grande parte das usinas foram privatizadas, o que acarretou na venda das UHE para empresas privadas.

No caso de Barra Grande, o Consórcio vencedor do leilão, responsável pela construção e operação da usina já desde o inicio foi privado. Com isso a negociação com os atingidos teve inúmeras dificuldades. Desde a falta de informação, que não é suficientemente clara para a população, passando pelas propostas de indenização que eram extremamente irrelevante frente as perdas sofridas pelos atingidos. Como consta no trecho a seguir, elaborado pelo Conselho de Defesa dos Direitos da Pessoa Humana/ Comissão Especial "Atingidos por Barragens" :

(...) os processos de planejamento, implementação e operação de barragens, muitas vezes, são precedidos e acompanhados por informação insuficiente, inconsistente, incompleta, omissa configurando campanhas publicitárias que visam conquistar adesões, ao invés de promover a conscientização das populações atingidas e outros interessados acerca da dimensão das mudanças, sociais e ambientais (CDDPH, 2010, p. 38).

\footnotetext{
${ }^{9}$ O Acordo realizado em 1987 foi fruto da luta dos atingidos perante a Eletrosul, subsidiária da Eletrobras responsável pelo setor elétrico na região sul do Brasil e que na época coordenava a construção da UHE Itá. O Acordo foi assinado por entre a CRAB (Comissão Regional dos Atingidos por Barragens) e a Eletrosul e tornouse referencia para a construção de reassentamentos dali em diante.
} 
Como relatamos anteriormente a hidroelétrica Barra Grande contribuiu significativamente para transformar o espaço da região de abrangência de sua instalação. E em grande medida alagou terras férteis, destruiu mata nativa, expulsou camponeses de suas terras, diminuiu empregos e consequentemente agrediu a economia da região. Todos esses problemas provocaram uma conflitualidade que se avolumou tornando-se contraditória e inegociável entre o consórcio que construiu a barragem e os atingidos pelo empreendimento, além de ambientalistas e algumas universidades.

As hidrelétricas, ao ocuparem um espaço, ao territorializarem-se, causam um forte impacto nas territorialidades pré-existentes, sejam elas sociais, políticas ou econômicas. Dessa forma a construção de hidrelétricas tem sentido não apenas como processo de artificialização da natureza ou de substituição de um meio natural por um meio técnico, mas, principalmente, como processo de des-territorialização e reterritorialização, o que significa fazer menção à dinâmica de criação de um novo território e do surgimento de novas territorialidades (Carvalho, 2006, p. 21).

O impacto causado e a trajetória de luta dos atingidos em outras usinas próximas com a influencia da organização do Movimento dos Atingidos por Barragens foi determinante para a organização dos atingidos por Barra Grande. Com isso a luta principal passou a ser por reassentamentos para compensar o fato de que as famílias seriam desapropriadas.

Os camponeses foram reassentados construíram, portanto um processo de (re)territorialização. Essa reconstrução feita pelos camponeses podemos entende-la apartir do que Milton Santos chama de força do lugar. Para ele, apesar da racionalidade capitalista impor uma ordem global com objetivo de aumentar a mais-valia produzida, com regras e normas, existe uma força do lugar, que é emoção, solidariedade e busca de dignidade. Essa força é que conduziu os atingidos pela barragem de Barra Grande a lutar por seus direitos. Com diversos anos de organização conquistaram e construíram reassentamentos, foram indenizados e conseguiram territorializar-se produzindo assim um novo espaço geográfico. A seguir, na figura 2, os reassentamentos construídos pelas próprias famílias atingidas por três hidrelétricas na Bacia do Rio Uruguai.

Acreditamos que os reassentamentos são a força do lugar, a força de reação do povo organizado contra a racionalidade capitalista que impõe formas de exploração, incorporando técnicas globais. As ações efetivas para estabelecer contra-poderes têm como base o entendimento do espaço como território usado, "o território são formas, mas o território usado são objetos e ações, sinônimo de espaço humano, espaço habitado" (Santos e Souza, 1994, p. 16, em Espindola, 2009, p. 239). 
Figura 2. Reassentamentos na Região Sul oriundos das UHE Itá, Machadinho e Barra Grande

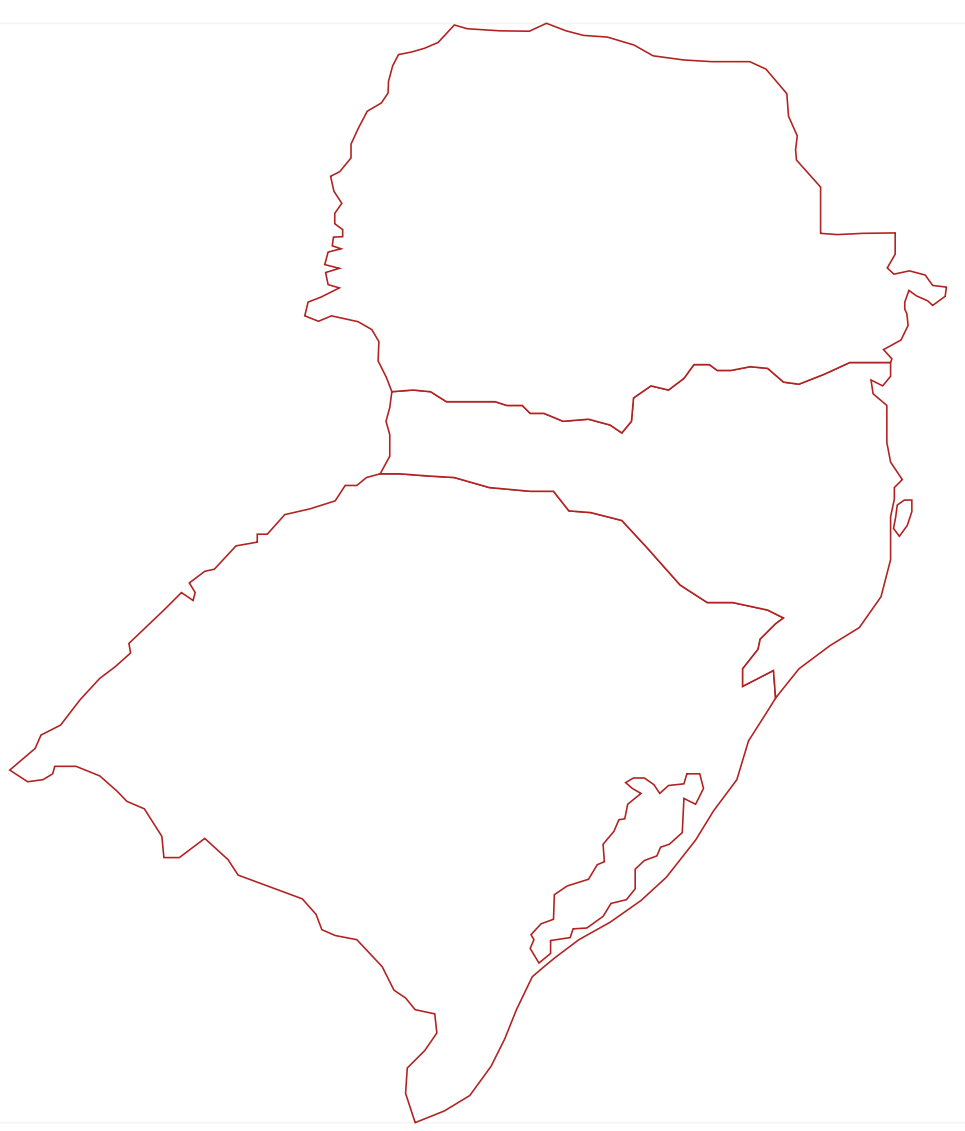

Elaborado com Philcarto * 19/2/2013 19:47:32 * http://philcarto.free.fr

Fonte: Arquivo MAB. Elaboração própria.

Foram reassentadas 192 famílias em municípios diferentes. A metodologia utilizada foi a compra de áreas grandes para divisão entre varias famílias. Com isso também alguns latifúndios passaram da posse de fazendeiros para camponeses. A construção das casas se deu de forma coletiva. O consórcio BAESA propôs fazer as casas contratando empresas da construção civil, porém os atingidos se dispuseram a construir. Com isso conseguiram fazer casas em média $30 \%$ maiores (de 42 para $56 \mathrm{~m}$ e de 64 para $90 \mathrm{~m}$ quadrados), além disso, economizaram dinheiro e fizeram sobrar recursos para comprar maquinário agrícola e parte de estruturas comunitárias.

Os atingidos conquistaram junto ao Consórcio BAESA projeto de assistência técnica durante cinco anos para os reassentamentos, além de estruturas comunitárias (salão comunitário, Igreja, cancha de laço ou cancha de bocha que são jogos típicos na região).

Atualmente os reassentamentos dessa região tem se articulado também com as comunidades ribeirinhas, que são comunidades de famílias que continuam morando próximas ao lago e também sofrem consequências da construção da hidrelétrica. Com isso estão propondo novas formas de produzir alimentos, de forma saudável e sustentável. As comunidades produzem 
especialmente alimentos para consumo próprio, além de priorizar a venda in natura, desde frutas, legumes e verduras, vendidos em programas governamentais e entregues para famílias carentes das cidades, escolas municipais e estaduais, alem de feiras livres nas cidades próximas.

A ordem local e a ordem global convivem e contradizem-se mutuamente nesse espaço que está permanentemente em transformação. A usina que está gerando energia há mais de sete anos é imponente na paisagem, e tem um poder de transformação do espaço diariamente. Diversas famílias que continuam morando na beira do lago sofrem as consequências de pouca estrutura que restou nas comunidades e mesmo de poucas pessoas. Os municípios atingidos, apesar do desenvolvimento prometido continuam com estradas precárias e os investimentos públicos não aumentaram. No entanto o lucro obtido com a venda da energia é destinado às empresas acionistas que funcionam com a lógica da racionalidade capitalista global.

De o outro lado as famílias permanecerem na terra, enfrentando inúmeros desafios e propondo enfrentar essa nova configuração espacial.

\section{CONSIDERAÇÕES FINAIS}

A barragem de Barra Grande transformou profundamente o espaço da região de abrangência atingida pela obra e pelo alagamento produzido. $\mathrm{O}$ objeto técnico hidrelétrica, planejado desde uma racionalidade capitalista global tem como meta gerar energia para produzir cada vez maior mais-valia. Os objetos técnicos que compõe o sistema estão interligados e interconectados de forma a produzir energia como bem de consumo e bem de produção. Esta racionalidade global não respeitou e continua não respeitando a realidade do lugar. No entanto, a força do lugar está presente e entra em conflitualidade com o global. Os atingidos pela barragem de Barra Grande estabeleceram conflitualidade, ao lutarem por seus direitos e ainda continuam organizados. É a esperança de que a racionalidade capitalista não seja a única a impor regras e explorar os bens naturais que são patrimônio de todo povo e da natureza.

\section{BIBLIOGRAFIA}

Amigos da Terra. Grandes e Pequenas Centrais Hidrelétricas na Bacia do Rio Uruguai: Guias para ONGs e Movimentos Sociais. Coordenação e revisão: Anelise Hüffner e Bruna Cristina Engel. Porto Alegre: Atual, 2011.

Brasil. Agéncia Nacional de Energia Elétrica. Banco de Informações de Geração: Capacidade de Geração Brasil. Disponível em:

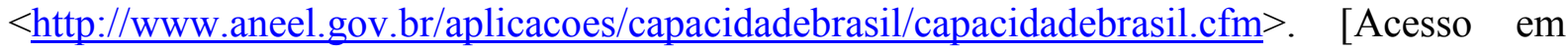
$17 / 02 / 2013]$.

Brasil. Agéncia Nacional de Energia Elétrica. Banco de Informações de Geração: Capacidade de Geração no Estado. Disponível em: $<$ http://www.aneel.gov.br/aplicacoes/ResumoEstadual/CapacidadeEstado.cfm? cmbEstados $=\mathrm{S}$ C:SANTA\%20CATARINA>. [Acesso em 18/02/2013]. 
Brasil. Eletrobras: Quem Somos. Disponível em: $<$ http://www.eletrobras.com/elb/data/Pages/LUMIS482AEFCFPTBRIE.htm $>$. [Acesso em 04/03/2013].

Brasil. Secretaria de Direitos Humanos da Presidência da República. Conselho de Defesa dos Direitos da Pessoa Humana. Comissão Especial “Atingidos por Barragens”. Brasília, 2011.

Baesa. Energia: Usina Hidrelétrica Barra Grande. Disponível em: $<$ http://www.baesa.com.br/baesa/categoria.php?\&cod_modulo=1\&cod categoria=1 $>$. [Acesso em 04/02/2013].

CARVALHO, Orlando Albani de. Água sobre Terra: Lugar e Territorialidade na Implantação de Grandes Hidrelétricas. Dissertação (Mestrado em Geografia). Porto Alegre: UFRGS/PPGEA, 2006.

CERVINSKI, Gilberto Carlos. A materialização do setor elétrico na Bacia do Rio Uruguai. Trabalho de Conclusão de Curso de Especialização. IPPUR/UFRJ. 2010.

Engevix. UHE Barra Grande - Relatório de Impacto ao Meio Ambiente - RIMA, 1997.

ESPINDOLA, Marcos Aurélio. As Transterritorializações na Bacia do Rio Uruguai e o alagamento sistemático de coletividades. Tese (Doutorado em Geografia). Programa de Pós Graduação em Geografia. UFSC, 2009.

FERNANDES, Bernardo Mançano. Conflitualidade e desenvolvimento territorial In: Luta pela Terra, Reforma Agrária e Gestão de Conflitos no Brasil. Campinas: Editora da Unicamp, 2008, p. 173-324.

GIRARDI, Eduardo Paulon. Manual de utilização do programa Philcarto 4.XX para Windows. Presidente Prudente: [s.n.], 2007. Disponível em: <www.fct.unesp.br/nera/atlas $>$. [Acesso em 02/02/2013].

PROCHNOW, Mirian. Barra Grande: a Hidrelétrica que não viu a floresta. Rio do Sul: APREMAVI, 2005.

SANTOS, Milton. A natureza do espaço: técnica e tempo, razão e emoção. São Paulo: Hucitec, 1996.

SILVA, Marcos Roberto da. Conflito e Negociação: estudo de caso em uma Usina Hidrelétrica. Trabalho de Conclusão de Curso (Graduação em Administração). Belo Horizonte: Instituto Metodista Izabela Hendrix, 2011. 
(C) Copyright Alexandra Borba da Silva, 2013.

(c) Copyright GeoGraphos, 2013.

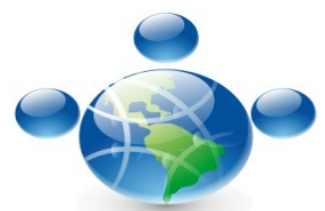

GIECRYAL

GRUPO INTERDISCIPLINARIO DE

ESTUDIOS CRÍTICOSY DE AMÉRICA LATINA 